\title{
Modelling of a Two-Phase Thermosyphon Loop for Passive Air-Conditioning of a House in Hot and Dry Climate Countries
}

\author{
Abdoulaye 1 Diallo $^{1,2 *}$, Xavier Chesneau1, Idrissa Diaby², Djanfar El-Maktoume1,3 \\ ${ }^{1}$ Laboratoire de Modélisation Pluridisciplinaire et Simulations (LAMPS), Université de Perpignan Via Domitia, Perpignan, France \\ ${ }^{2}$ Laboratoire d'Enseignement et de Recherche en Energétique Appliquée (LEREA), Université Gamal Abdel Nasser de Conakry, \\ Conakry, Guinée \\ ${ }^{3}$ Laboratoire énergétique de l'équipe d'Accueil Doctoral physique du Globe, de l'Energie et de l'Environnement (PGEE), \\ Université d'Antananarivo, Antananarivo, Madagascar \\ Email: *abdulahjaloh@gmail.com, chesneau@univ-perp.fr
}

How to cite this paper: Diallo, A., Chesneau, X., Diaby, I. and El-Maktoume, D. (2021) Modelling of a Two-Phase Thermosyphon Loop for Passive Air-Conditioning of a House in Hot and Dry Climate Countries. Energy and Power Engineering, 13, 243-260.

https://doi.org/10.4236/epe.2021.136017

Received: May 20, 2021

Accepted: June 27, 2021

Published: June 30, 2021

Copyright $\odot 2021$ by author(s) and Scientific Research Publishing Inc. This work is licensed under the Creative Commons Attribution International License (CC BY 4.0).

http://creativecommons.org/licenses/by/4.0/

\section{(c) (i) Open Access}

\begin{abstract}
The two-phase thermosyphon loop is an efficient solution for space cooling. This paper presents the simulation results of numerical studies on the heat transfer and thermal performance of a two-phase thermosiphon loop for passive air-conditioning of a house. The fluid considered in this study is methanol, which is compatible with copper and is environmentally friendly. These numerical results show that the temperature at the evaporator wall drops from $23^{\circ} \mathrm{C}$ to $13^{\circ} \mathrm{C}$ and increases at the condenser. The solar flux density has a strong influence on the condenser temperature. The mass flow rates and masses at the evaporator and condenser increase with temperature. The variation of evaporating and condensing temperature affects the performance of the system. For a constant evaporating and condensing temperature of $2^{\circ} \mathrm{C}$ and $29^{\circ} \mathrm{C}$, the COP is 0.77 and 0.84 respectively. With these results, the use of the two-phase thermosyphon loop in air conditioning is possible to obtain a thermal comfort of the occupants acceptable by the standards but with a large exchange surface of the evaporator.
\end{abstract}

\section{Keywords}

Two-Phase Thermosiphon Loop, Modelling, Passive Air Conditioning, Thermal Performance

\section{Introduction}

The residential, commercial and office building sector is one of the largest con- 
sumers of energy in the world. Yet the current challenge is to reduce the energy consumption and cost caused by these buildings. However, in cities, buildings consume $70 \%$ of primary energy [1]. In hot and humid countries, the ambient temperature and relative humidity can reach $41^{\circ} \mathrm{C}$ and $84 \%$ respectively. In these tropical countries, air conditioning becomes essential to maintain thermal comfort conditions for humans in buildings. These indoor conditions should be maintained around $20^{\circ} \mathrm{C}-25^{\circ} \mathrm{C}$ with a relative humidity of $50 \%-55 \%$ according to ASHRAE (2013) and ISO 7730-2005 [2]; $23^{\circ} \mathrm{C}-26^{\circ} \mathrm{C}$ in summer and $20^{\circ} \mathrm{C}$ $23.5^{\circ} \mathrm{C}$ in winter, according to other standards [3]. Air-conditioning and ventilation systems are among the largest energy consumers in countries or regions with relatively high air temperatures. Air conditioning equipment can consume up to $50 \%-80 \%$ of the total electricity consumption of residential, public and commercial buildings in both developed and developing countries [2]. In developing countries such as Guinea, the cost of electricity for the consumer from recently completed hydroelectric dams and conventional fossil fuel power plants continues to rise due to high transmission and distribution losses. In order to address this energy crisis and to improve the comfort of the population, it is urgent and important to develop a passive air-conditioning system using a two-phase thermosyphon loop for these buildings in order to reduce their consumption, greenhouse gas emissions and to fight global warming.

So far, the two-phase closed thermosyphon loop is less used in passive air conditioning in the home, but is widely applied in the cooling of electronic equipment. This loop is a natural two-phase flow cycle that can achieve efficient and low-cost heat transfer [4].

Numerous studies on closed-loop two-phase thermosyphon have been conducted in the literature.

Cao et al. [4] carried out a study on Variable Conductance Loop Thermosiphon (VCLT) active thermal control for thermal comfort in buildings based on steady state heat transfer modelling. They showed that under normal conditions, opening the control valve from 1 to 0.77 results in a decrease in heat transfer rate from $468.5 \mathrm{~W}$ to $71.9 \mathrm{~W}$ and an increase in internal flow resistance from 0.002 $\mathrm{K} / \mathrm{W}$ to $0.305 \mathrm{~K} / \mathrm{W}$.

Samba et al. [5] carried out an experimental study of a two-phase thermosiphon loop using a telecommunication cabinet to cool telecommunication equipment with n-pentane as the working fluid. The results show that the optimum filling ratio is $9.2 \%$.

Han et al. [6] developed a thermosyphon loop air conditioner combined with a vapour compression refrigerator for cooling a mobile phone base station. They showed that the COP of the thermosyphon loop reaches 9.43 when the outdoor temperature is $20^{\circ} \mathrm{C}$ lower than the indoor temperature. Field tests also show that the thermosyphon saves about $34.3 \%$ to $36.9 \%$ energy compared to the traditional air conditioner.

Zhu et al. [7], for space heating, proposed a two-phase thermosyphon loop (TPTL) integrated in a building envelope to replace a pump-driven heat injec- 
tion process system. The results showed a critical impact of the fill rate on the thermal resistance and on the behaviour of the thermosyphon loop during start-up. They also revealed that the fill rate of about $116 \%$ is not a fixed value and can be reduced to achieve a higher start-up speed or increased to achieve a lower thermal load resistance.

An experimental study was carried out by Tong et al. [8], on the self-regulation performance of a two-phase dual evaporator thermosyphon loop based on R744, used in data center air conditioning systems. The experimental analyses show that the mass flow rate of the high-power evaporator is higher than that of the low power evaporator with a very limited self-regulation capacity of the TPTL. In addition, they found that in practical applications with a parallel multi-evaporator TPTL system, a large difference between the heat transfer loads to the evaporators must be avoided.

In the research work of Ding et al. [9], they studied a heat pipe system compared to a traditional air conditioning system for a computer room. These results showed that the system can maintain the computer room at a temperature of $17^{\circ} \mathrm{C}$ to $21^{\circ} \mathrm{C}$ for the proper functioning of the computer equipment.

Khodabandeh [10], made an experimental study of a closed two-phase thermosiphon loop for cooling high heat flux electronic components of a radio base station. The tests were carried out with isobutane (R600a) as working fluid. It proves that in the thermosyphon loop system, the thermal resistances between the heat source/evaporator and the condenser/air dominate over the resistances between the evaporator walls and the condenser walls.

The objective of this study is to numerically model a two-phase thermosyphon loop for passive air conditioning in hot and dry tropical countries such as Guinea in the Mamou region using the finite element method. With high ambient temperatures mainly caused by solar irradiation and the effect of global warming in this country will increase the need and seasonal demand for space cooling in the future.

\section{Description of the Physical Model of the System Studied}

The two-phase thermosyphon loop (TPTL) is a reliable and energy-efficient heat transfer device based on fluid buoyancy.

In general, thermosyphons work by using a heat transfer fluid with a well-controlled amount injected into the liquid reservoir. The dissipation of heat from the system to be cooled leads to a phase change of the heat transfer fluid under a saturation pressure [11].

The air-conditioning system studied is a simple, fully self-contained design. It consists of an evaporator, a condenser, a riser and a downcomer (Figure 1). The evaporator is placed in the room to be cooled and the condenser outside the room. However, it should be noted that the evaporator and the condenser are plate heat exchangers. The condenser should be positioned at a higher altitude than the evaporator with some vertical distance [12]. The working fluid absorbs 


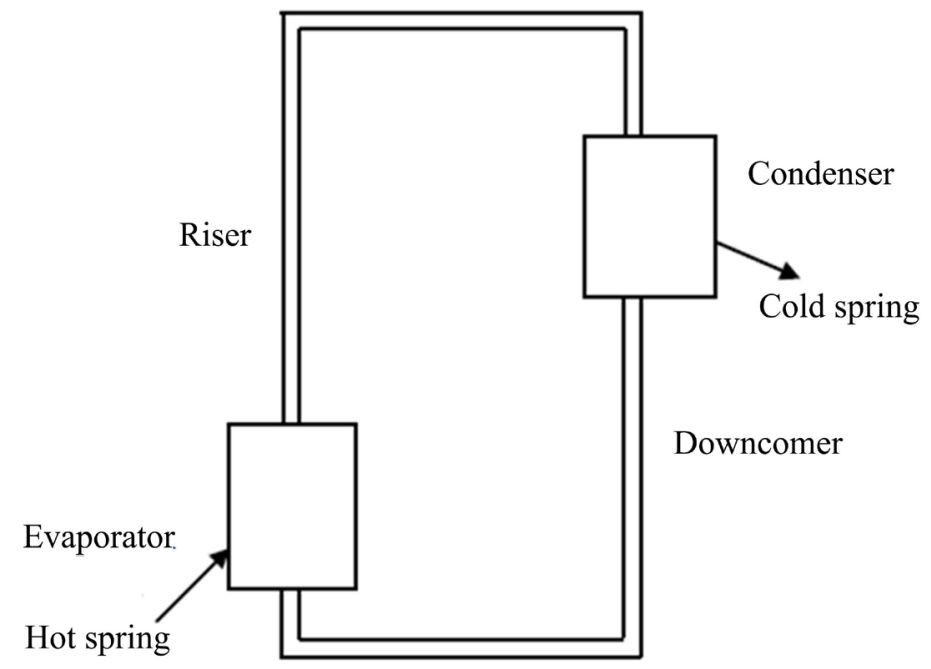

Figure 1. Schematic of the two-phase thermosyphon loop air conditioning system.

heat from the room and evaporates in the evaporator. The mass of vapour rises in the riser due to the buoyancy forces caused by the differences in density of the fluid in the riser and the downcomer. It condenses in the condenser, releasing its latent heat of condensation. The condensate flows by gravity into the downcomer and back into the evaporator. This cycle is an excellent heat carrier only by natural convection in closed loops and eliminates the need for a conventional pump to circulate the heat transfer fluid.

The material used in the various components of the two-phase thermosyphon loop is copper, with methanol as the working refrigerant.

\section{- Thermo-physical properties of materials}

The thermal properties of the materials in the system are assumed to be constant over time (Table 1).

\section{Physical Modelling of Heat Transfer in the Air Conditioning System}

\subsection{Basic Equations}

The basic equation governing the evolution of the temperature in the different sections of the air conditioning system over time is written in the following general form [13]:

$$
\frac{m_{i} C p_{i}}{S_{i}} \frac{\partial T_{i}}{\partial t}=D F S_{i}+\sum_{i} h_{x i j}\left(T_{j}-T_{i}\right)+\Phi_{i}
$$

This Equation (1) will be applied to the various components of the two-phase thermosyphon loop.

\subsection{Heat Transfer Balance at the Evaporator and Condenser}

The evaporator is the main part of the loop, where the liquid boils. Heat is transferred as heat of vaporisation from the evaporator to the condenser. Figure 2 illustrates the points considered for evaluating the different temperatures. 
Table 1. Thermo-physical properties of materials.

\begin{tabular}{|c|c|c|c|c|}
\hline \multicolumn{2}{|c|}{ Materials } & Density $\rho\left(\mathrm{kg} / \mathrm{m}^{3}\right)$ & Heat capacity $C p(\mathrm{~J} / \mathrm{kg} \cdot \mathrm{K})$ & $\begin{array}{c}\text { Thermal conductivity } \lambda \\
(\mathrm{W} / \mathrm{m} \cdot \mathrm{K})\end{array}$ \\
\hline \multicolumn{2}{|c|}{ Air } & 1.16 & 1006 & 0.0261 \\
\hline \multicolumn{2}{|c|}{ Copper } & 8900 & 380 & 380 \\
\hline \multirow{2}{*}{ Methanol } & Liquid & 786 & 4390 & - \\
\hline & Vapour & 0.218 & 1400 & - \\
\hline
\end{tabular}

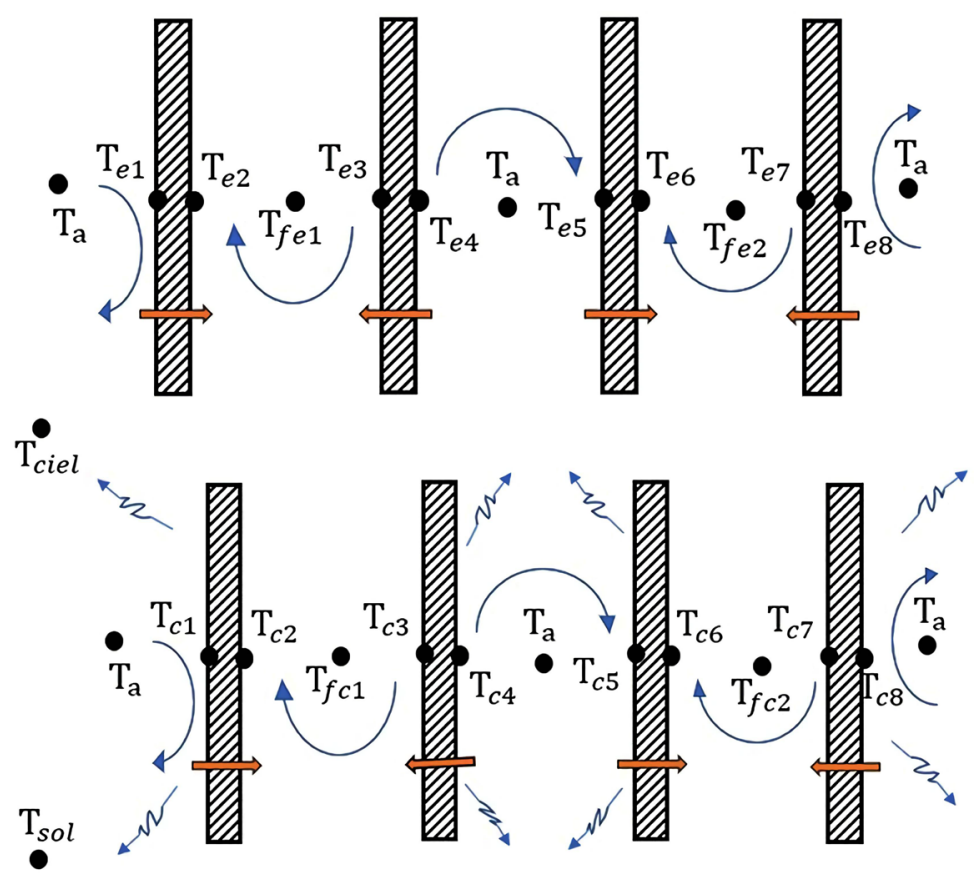

Figure 2. The different modes of heat transfer at the evaporator and condenser.

\section{- For external walls}

Evaporator:

$$
m c_{p} \frac{\partial T_{e i}}{\partial t}=h_{c} S\left(T_{a}-T_{e i}\right)+h_{c o n d} S\left(T_{e j}-T_{e i}\right)
$$

Condenser:

$$
\begin{aligned}
m c_{p} \frac{\partial T_{C i}}{\partial t}= & \alpha G_{n} S+h_{c} S\left(T_{a}-T_{C i}\right)+h_{\text {cond }} S\left(T_{C j}-T_{C i}\right) \\
& +h_{r, \text { sol }} S\left(T_{\text {sol }}-T_{C i}\right)+h_{r, \text { ciel }} S\left(T_{\text {ciel }}-T_{C i}\right)
\end{aligned}
$$

\section{- For internal walls}

Evaporator:

$$
m c_{p} \frac{\partial T_{e j}}{\partial t}=h_{c o n d} S\left(T_{e i}-T_{e j}\right)+h_{c} S\left(T_{f e}-T_{e j}\right)
$$

Condenser:

$$
m c_{p} \frac{\partial T_{C j}}{\partial t}=h_{\text {cond }} S\left(T_{C i}-T_{C j}\right)+h_{c} S\left(T_{f C}-T_{C j}\right)
$$




\section{- At the fluid}

Evaporator:

$$
m_{f} c_{p f} \frac{\partial T_{f e}}{\partial t}=h_{c} S\left(T_{e j}-T_{f e}\right)+h_{c} S\left(T_{e j^{\prime}}-T_{f e}\right)-\dot{m} h_{f g}
$$

Condenser:

$$
m_{f} c_{p f} \frac{\partial T_{f C}}{\partial t}=h_{c} S\left(T_{C j}-T_{f C}\right)+h_{c} S\left(T_{C j^{\prime}}-T_{f C}\right)+\dot{m} h_{f g}
$$

The volume flow rate from the evaporator to the riser is calculated by:

$$
\frac{\mathrm{d} m}{\mathrm{~d} t}=\dot{m}=S \beta_{m}\left[w_{v s}\left(T_{s}\right)-w_{v}(T)\right]
$$

\subsection{Heat Transfer Balance for Riser and Downcomer}

The evaporator is connected to the condenser by pipes called the riser and the downcomer. In the riser (Figure 3(a)), the mass of steam produced at the evaporator rises through this pipe and flows to the condenser where it condenses. The condensate flows by gravity into the downcomer (Figure 3(b)) and returns to the evaporator as a liquid. Figure 3 shows the different points considered for temperature evaluation.

General equation

$$
\begin{gathered}
m c_{p} \frac{\mathrm{d} T}{\mathrm{~d} t}=\sum_{i} h_{i} S_{i} \Delta T_{i} \quad \frac{\mathrm{d} T_{i}}{\mathrm{~d} t}=\frac{\partial T}{\partial t}+U \frac{T_{i}-T_{i-1}}{\Delta x} \\
P u=m c_{p} U \frac{T_{i}-T_{i-1}}{\Delta x} \text { hence } \frac{\mathrm{d} T_{i}}{\mathrm{~d} t}=\frac{\partial T}{\partial t}+P u
\end{gathered}
$$

\section{- Equation for the external wall}

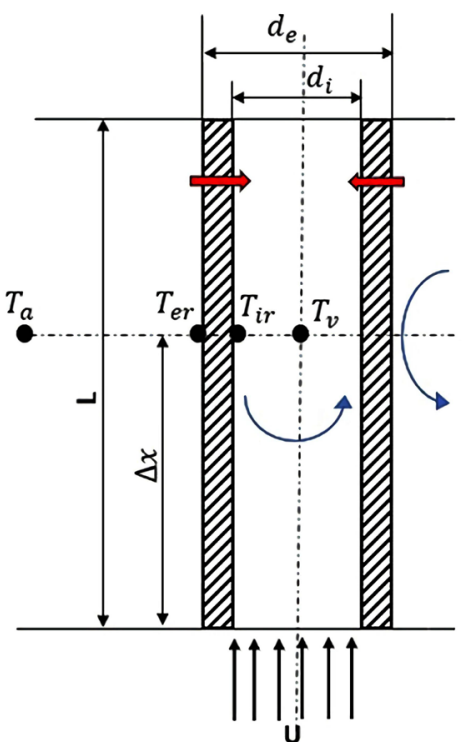

(a)

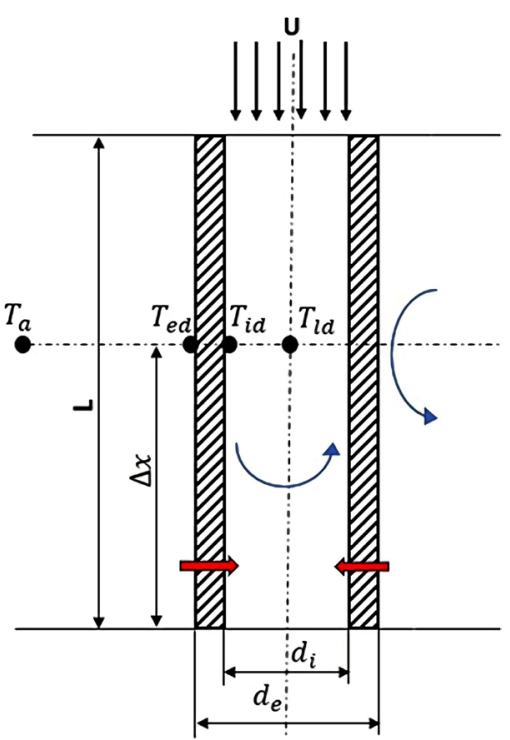

(b)

Figure 3. The different modes of heat transfer for the Riser (a) and for the downcomer (b). 
Riser.

$$
m c_{p} \frac{\partial T_{e r}}{\partial t}=h_{c} S\left(T_{a}-T_{e r}\right)+S \frac{\lambda}{e_{p}}\left(T_{i r}-T_{e r}\right)
$$

Downcomer

$$
m c_{p} \frac{\partial T_{e d}}{\partial t}=h_{c} S\left(T_{a}-T_{e d}\right)+S \frac{\lambda}{e_{p}}\left(T_{i d}-T_{e d}\right)
$$

\section{- Equation for the internal wall}

Riser.

$$
m c_{p} \frac{\partial T_{i r}}{\partial t}=S \frac{\lambda}{e_{p}}\left(T_{e r}-T_{i r}\right)+h_{c} S\left(T_{v}-T_{i r}\right)
$$

Downcomer

$$
m c_{p} \frac{\partial T_{i d}}{\partial t}=S \frac{\lambda}{e_{p}}\left(T_{e d}-T_{i d}\right)+h_{c} S\left(T_{l d}-T_{i d}\right)
$$

\section{- Equation for methanol}

For methanol in the vapour state:

$$
m_{v} c_{p}\left(\frac{\partial T_{v}}{\partial t}+P\right)=h_{c} S\left(T_{i r}-T_{v}\right)
$$

For methanol in the liquid state:

$$
m_{f} c_{p f}\left(\frac{\partial T_{l d}}{\partial t}+P\right)=h_{c} S\left(T_{i d}-T_{l d}\right)
$$

\subsection{Determination of Heat Transfer Coefficients}

- The coefficients of conductive heat transfer through the thickness of these materials are given by the following formula:

$$
h_{\text {cond }, i}=\frac{\lambda_{i}}{e_{p i}}
$$

- The convective exchange coefficient between the external walls of the condenser and the ambient air is given by the following expression [14]:

$$
h_{c e}=5.7+3.8 \times V
$$

- The natural convection heat transfer coefficients between the vertical inner walls between the air in the habitat enclosure and the vertical outer walls of the evaporator are determined using the correlation proposed by Churchill and Chu [15]:

$$
N u=0.68+\frac{0.67(R a)^{1 / 4}}{\left\{1+\left(\frac{0.492}{P r}\right)^{9 / 16}\right\}^{4 / 9}} ; \quad R a \leq 10^{9}
$$

- The heat transfer coefficient between the refrigerant and the inner walls of the evaporator [16], which assumes nucleated boiling, is calculated by the following relationship: 


$$
h_{e}=0.00122\left\{\frac{c_{p l}^{0.45} \rho_{l}^{0.49} \lambda_{l}^{0.79}}{\sigma_{f}^{0.5} h_{f g}^{0.24} \mu_{l}^{0.29} \rho_{v}^{0.24}} \Delta T_{\text {sat }}^{0.24} \Delta P_{s}^{0.75}\right\}
$$

- The natural convection transfer coefficient during condensation between the fluid and the inner walls of the condenser is calculated by [17]:

$$
h_{c}=0.943\left\{\frac{\rho_{l} g \lambda_{l}^{3} h_{f g}\left(\rho_{l}-\rho_{v}\right)}{\mu_{l} L_{c}\left(T_{s a t}-T_{p}\right)}\right\}^{1 / 4}
$$

- The radiative transfer coefficients between the external walls and the sky and between the external walls and the ground are determined using the following relationships [14]:

$$
\begin{gathered}
h_{r, \text { ciel }}=\frac{\sigma\left(T_{p}+T_{\text {ciel }}\right)\left(T_{p}^{2}+T_{\text {ciel }}^{2}\right)}{\frac{1}{\varepsilon}+\frac{1}{F_{\text {ciel }}}-1} ; T_{\text {ciel }}=0.0552\left(T_{a}\right)^{1.5} \\
h_{r, \text { sol }}=\frac{\sigma\left(T_{p}+T_{\text {sol }}\right)\left(T_{p}^{2}+T_{\text {sol }}^{2}\right)}{\frac{1}{\varepsilon}+\frac{1}{F_{\text {sol }}}-1}
\end{gathered}
$$

\section{Coefficient of Performance}

\section{Coefficient of thermal performance $\left(C O P_{t h}\right)$}

The efficiency of the machine is expressed by the thermal coefficient of performance $C O P_{t h}$ given by the relation (22):

$$
C O P_{\text {th }}=\frac{Q_{f}}{Q_{\text {chaleur }}}
$$

$Q_{f}:$ Is the power at the evaporator in $(W)$, which is given by the relation:

$$
Q_{f}=\dot{m}_{f}\left[h_{f g}\left(T_{e v}\right)-C p_{l}\left(T_{c d}-T_{e v}\right)\right]
$$

$Q_{\text {chaleur }}$ : Amount of energy supplied to evaporate the fluid in $(W)$ given by the relation:

$$
Q_{\text {chaleur }}=\dot{m}_{f} C p_{l}\left(T_{\text {sat }}-T_{\text {entree }}\right)+\dot{m}_{f} h_{f g}\left(T_{e v}\right)
$$

\section{Results and Discussion}

The evaporator was validated from an experimental study by [8], who performed an experiment on the self-regulation performance of a two-phase thermosiphon loop with double parallel evaporators. They carried out the study with the refrigerant R744 in contrast to our system which operates with methanol as working fluid. The temperature on the surface of the evaporator is measured using Pt1000 sensors. The curve in Figure 4 shows that our results are in good qualitative agreement between our numerical simulation and the chosen experimental model. This result confirms the validity of our simulation model.

Figure 5 shows the evolution of the temperature of the fluid, the evaporated 


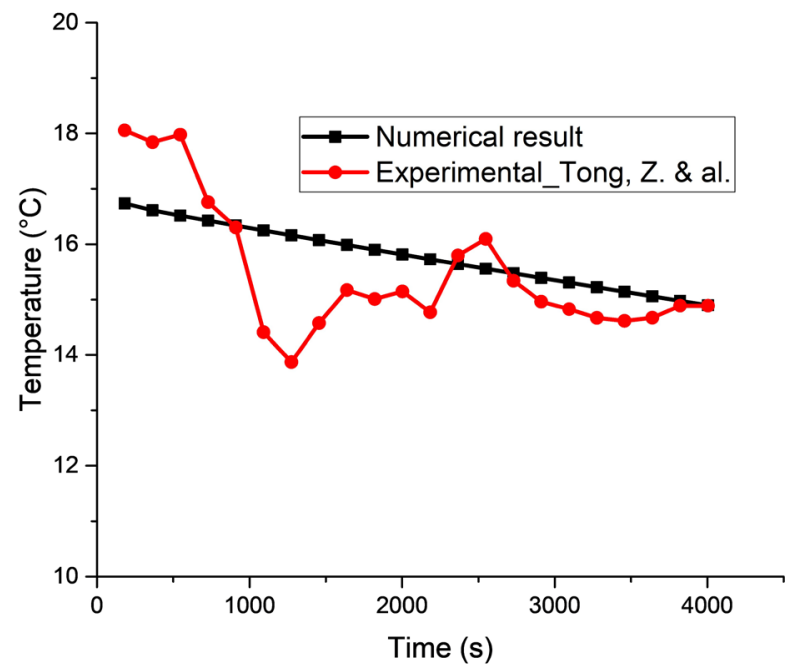

Figure 4. Validation of the evaporator.

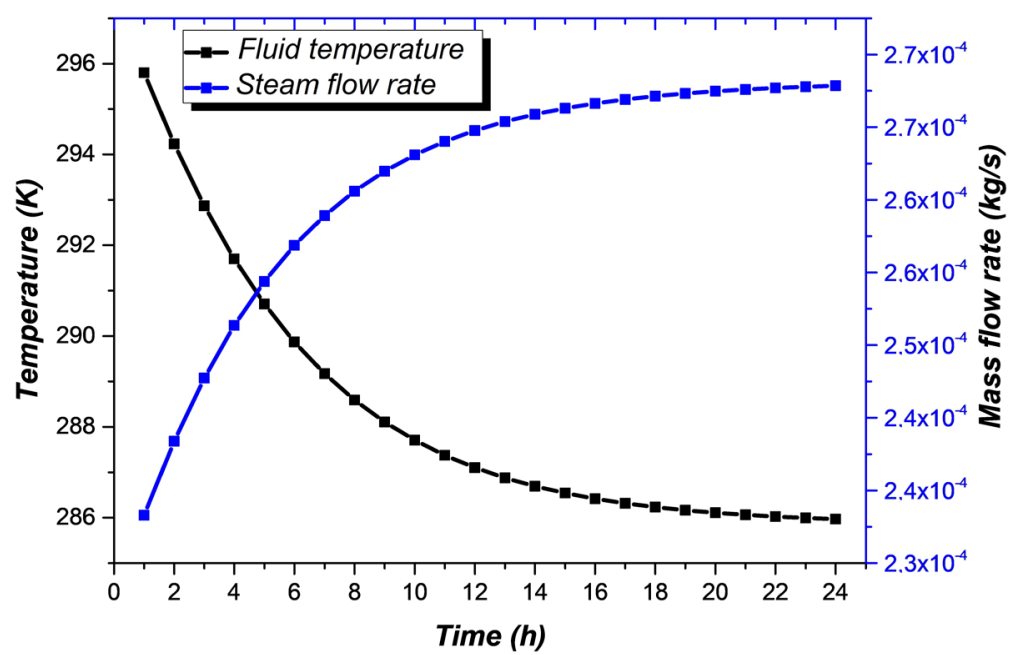

(a)

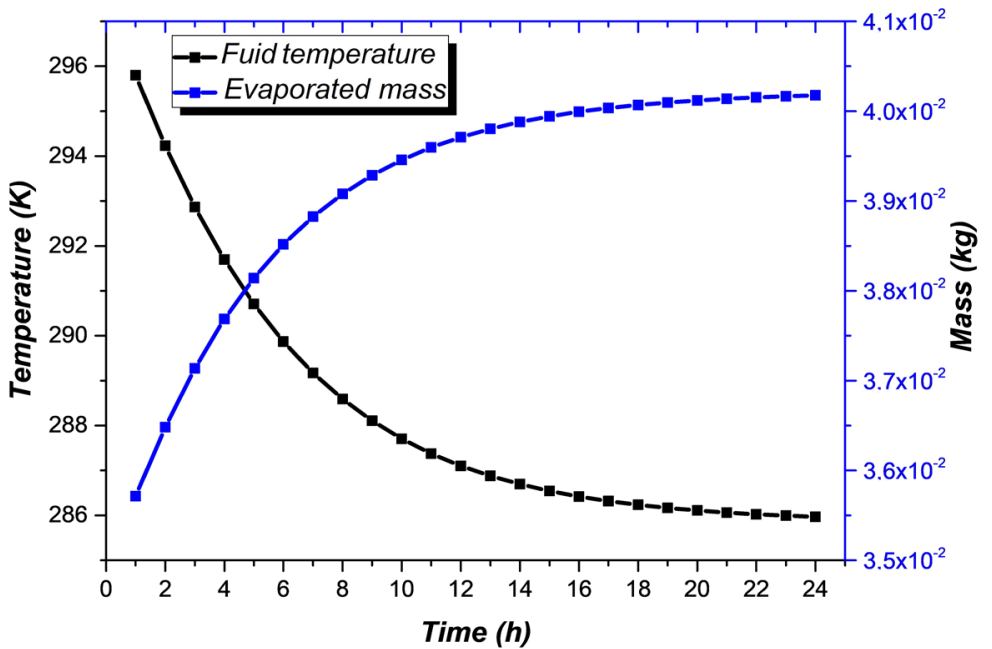

(b)

Figure 5. Evolution of the fluid temperature, mass (b) and flow rate (a) evaporated at the evaporator. 
mass and the flow rate of the vapour at the exit of the evaporator, this system works alone without coupling with a habitat. The simulation is carried out with a surface area of $S=2 \mathrm{~m}^{2}$. The ambient temperature is assumed to be constant over time. The decrease in temperature is justified by the fact that thermal heat is being extracted from the enclosure to be conditioned to the condenser, so we have a heat loss at this level. This drop in temperature shows the feasibility of our thermosiphon system on a large scale for thermal comfort in the home. We notice that the flow rate and the mass increase progressively. The presence of the mass and flow rate of the vapour at the outlet of the evaporator to the condenser shows us a natural circulation of the fluid and the entry of the vapour into the riser (Figure 5(a) and Figure 5(b). The steam produced passes through the riser before entering the condenser. The key role of the evaporator is to ensure superheating at the outlet and sub-cooling at the inlet for better air conditioning.

The condenser was validated from an experimental study by [7], who conducted experiments on a prototype to explore the operational characteristics of a two-phase thermosyphon loop (TPTL) for heating a building. To measure the temperature and pressure of the TPTL, four four-way connectors coupled to four Pt100 sensors were used. In Figure 6, we observe qualitatively, a comparable curve pattern between the results of our model simulation and the chosen experimental model. This pattern confirms the validity of our simulation model.

Figure 7 illustrates the temporal evolution of the fluid temperature, mass and flow rate at the condenser. As the condenser is located outside the building, it exchanges heat with the surrounding environment. The simulation was carried out with a surface $S=0.5 \mathrm{~m}^{2}$ and applying a constant solar flux of $700 \mathrm{~W} / \mathrm{m}^{2}$ on the outside walls, which are exposed to the sun. We can see that the temperature increases gradually over time until it reaches a maximum value of about $47^{\circ} \mathrm{C}$. This increase in the condenser temperature is mainly due to the release of heat

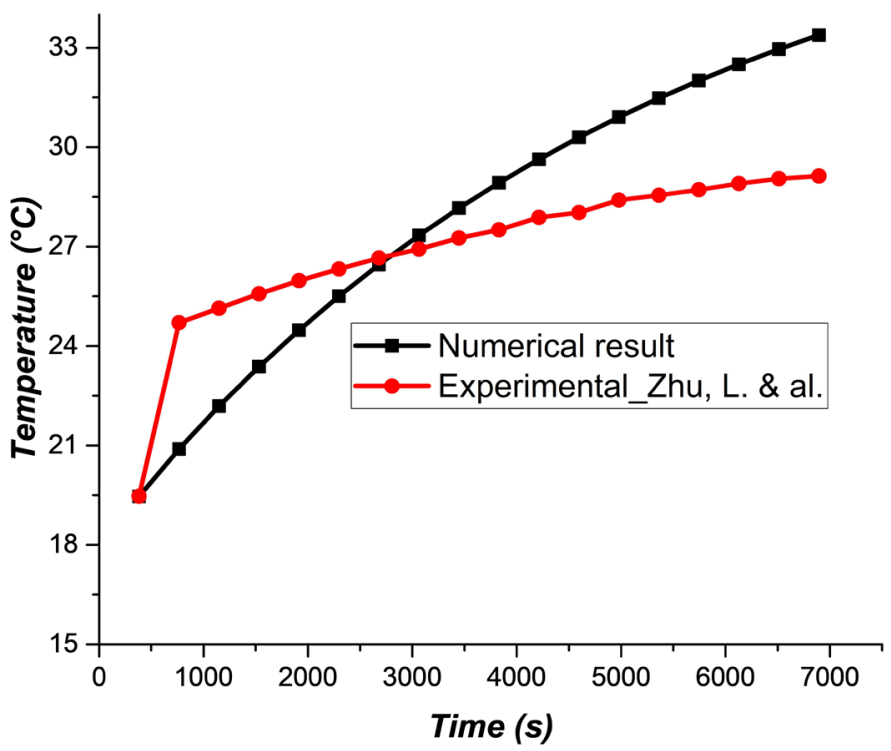

Figure 6. Condenser validation. 


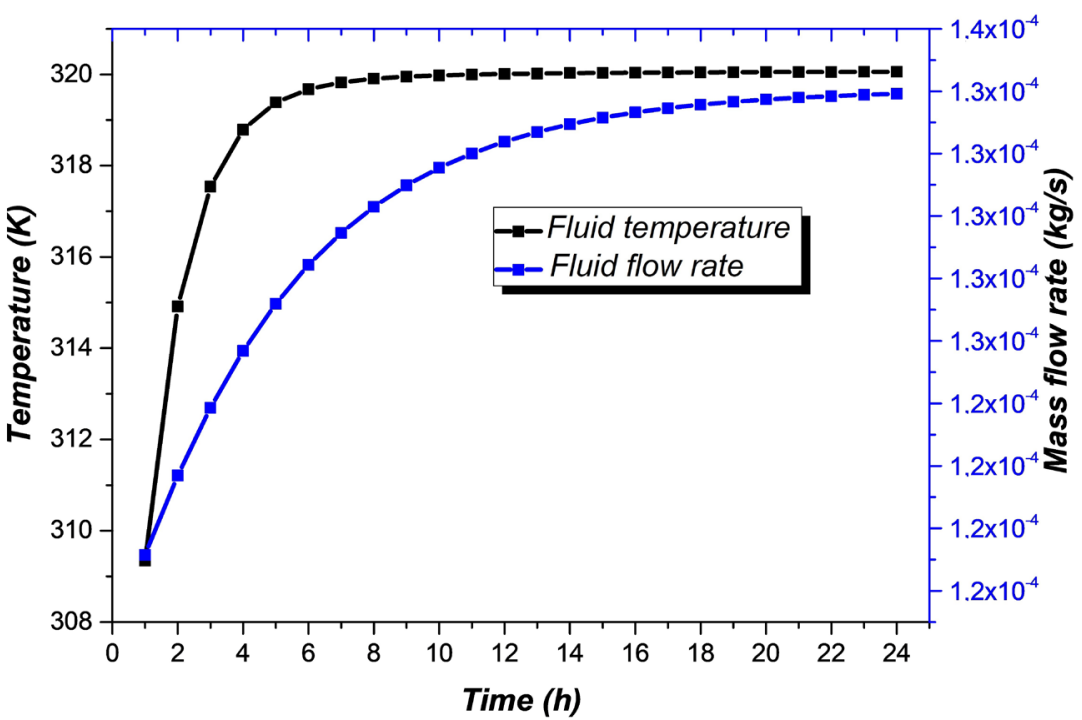

(a)

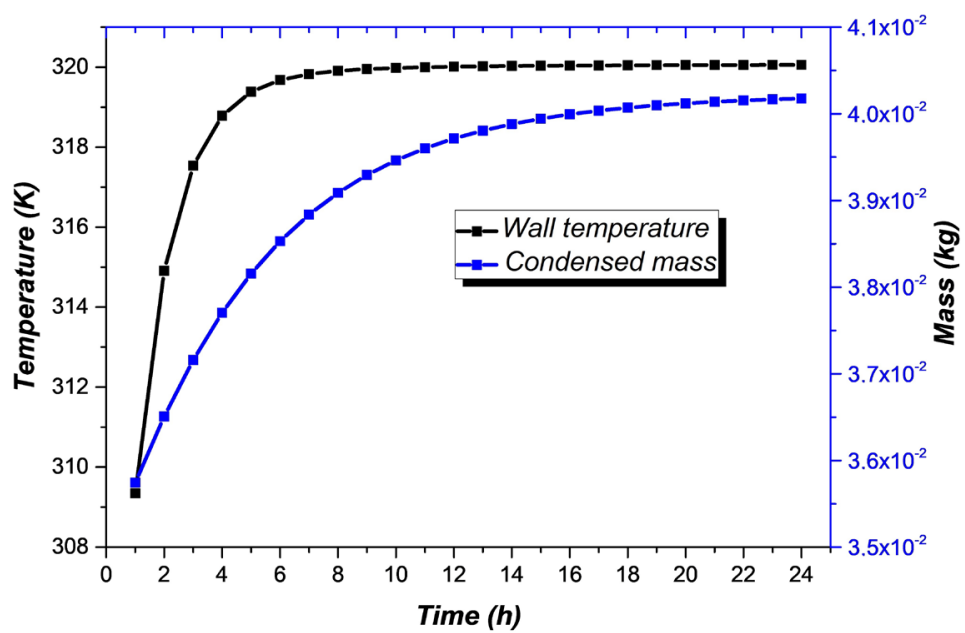

(b)

Figure 7. Evolution of fluid temperature, mass (b) and flow rate (a) condensed at the condenser.

when the methanol vapour condenses on the condenser walls and this is normal because we have a heat gain. We also notice that the increase in flow rate leads to an increase in evaporated mass. After the vapour enters the condenser, it releases latent heat with the exchange of heat from the surrounding environment and the liquid phase of the working heat transfer fluid is obtained at the condenser outlet. The decrease in flow rate (Figure 7(a)) at the condenser justifies an accumulation of the liquid at the downcomer before entering the evaporator to start a new cycle. These developments are comparable to practice.

Figure 8 illustrates the influence of the solar flux on the evolution of the fluid temperature at the condenser. We can see that the temperature increases gradually before stabilising because the solar flux reaching the condenser walls has been increased. Indeed, the more the sun's radiation on the walls of the condenser is important, the more the temperature increases as shown by the curves. 


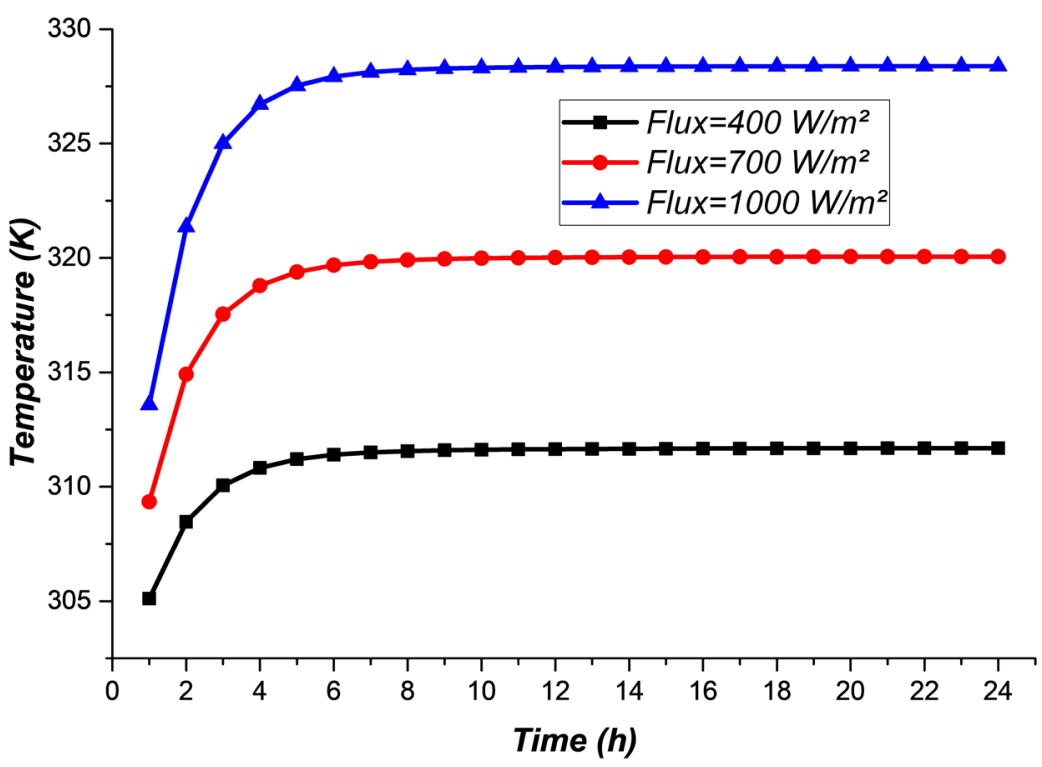

Figure 8. Evolution of the fluid temperature at the condenser with the variation of the solar flux.

The temperature varies according to the solar flux density, reaching a maximum of $55^{\circ} \mathrm{C}$ when the flux density is $1000 \mathrm{~W} / \mathrm{m}^{2}$ and a minimum of $39^{\circ} \mathrm{C}$ when the radiated flux density is $400 \mathrm{~W} / \mathrm{m}^{2}$. These evolutions represent the variation of the typical sunshine in the Mamou region during the dry season.

Figure 9 illustrates the influence of the evaporator surface area on the temporal evolution of the temperature. We notice that the temperature decreases less with increasing surface area because the air temperature is constant and is fixed at $25^{\circ} \mathrm{C}$. From the curves we can see that the surface area has a very important influence on the temperature, it increases when the surface area is large because the air temperature is constant and fixed at $25^{\circ} \mathrm{C}$. This means that the larger the surface area, the greater the heat exchange, it reaches $12^{\circ} \mathrm{C}$ when the surface is $S=0.5 \mathrm{~m}^{2}$ and about $14^{\circ} \mathrm{C}$ when the surface is $S=3 \mathrm{~m}^{2}$.

Figure 10 shows the influence of the evaporation temperature on the amount of cold produced and the thermal performance coefficient. It can be seen that when the evaporation temperature varies between $270 \mathrm{~K}$ and $284 \mathrm{~K}$, the thermal coefficient of performance and the amount of cold produced increase progressively with it, until reaching maximum values of 0.84 and $123.25 \mathrm{~W}$ respectively.

Figure 11 shows the influence of the condensing temperature on the amount of cold produced and the thermal performance coefficient. It can be seen that by keeping the evaporation temperature constant at $274 \mathrm{~K}$ and varying the condensation temperature from $302 \mathrm{~K}$ to $320 \mathrm{~K}$, the thermal coefficient of performance of the air conditioning system and the amount of cold produced gradually decrease until reaching minimum values of 0.77 and $114 \mathrm{~W}$ respectively.

Figure 12 shows the evolution of the fluid flow velocity in the vapour state in the riser and in the liquid state in the downcomer. We see a difference in velocity at the riser and downcomer due to the different density of methanol in the liquid 


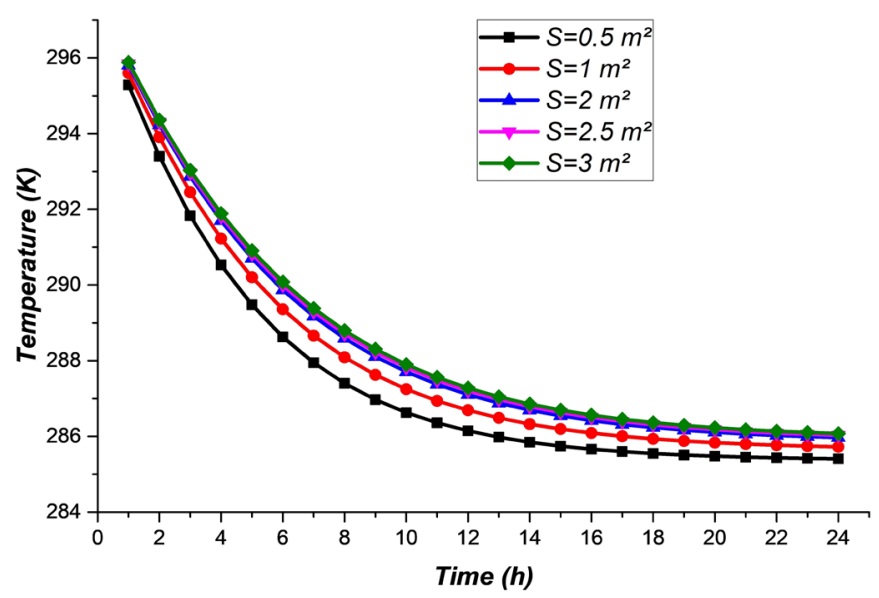

Figure 9. Evolution of the temperature of the fluid at the evaporator with the variation of the surface area.

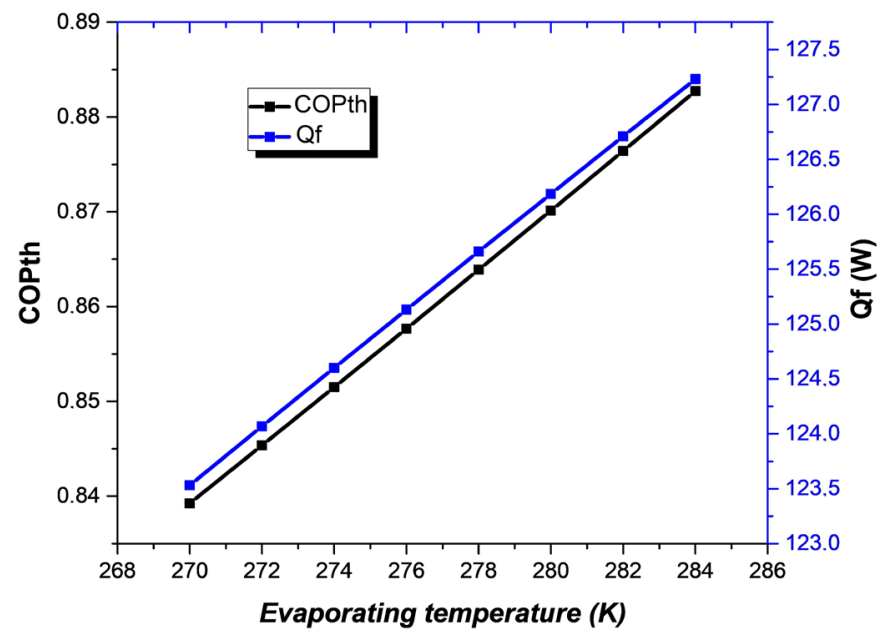

Figure 10. Influence of the evaporation temperature on the thermal performance coefficient and the amount of cooling with $T_{c d}=302 \mathrm{~K}$.

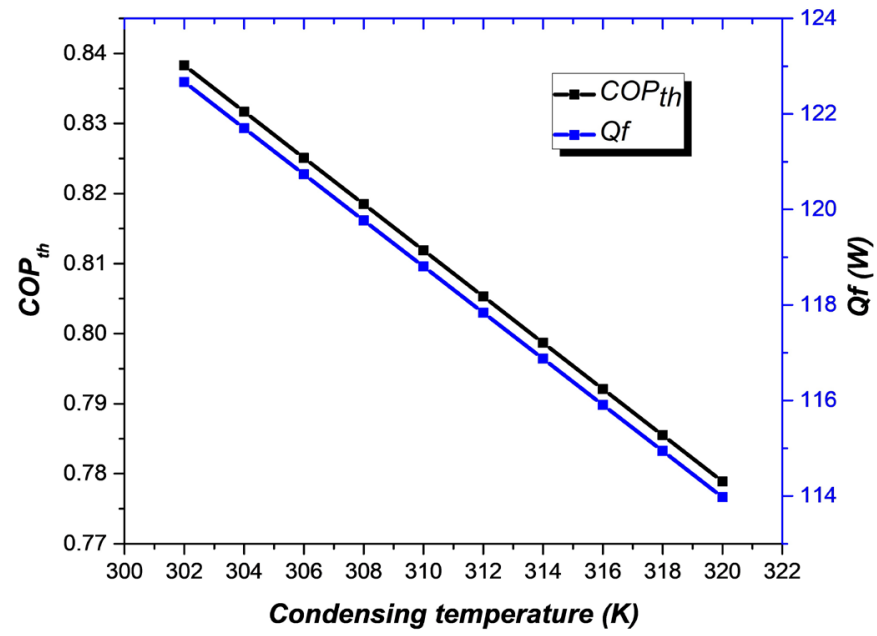

Figure 11. Influence of the condensation temperature on the thermal coefficient of performance and the amount of cooling with $T_{e V}=275 \mathrm{~K}$. 


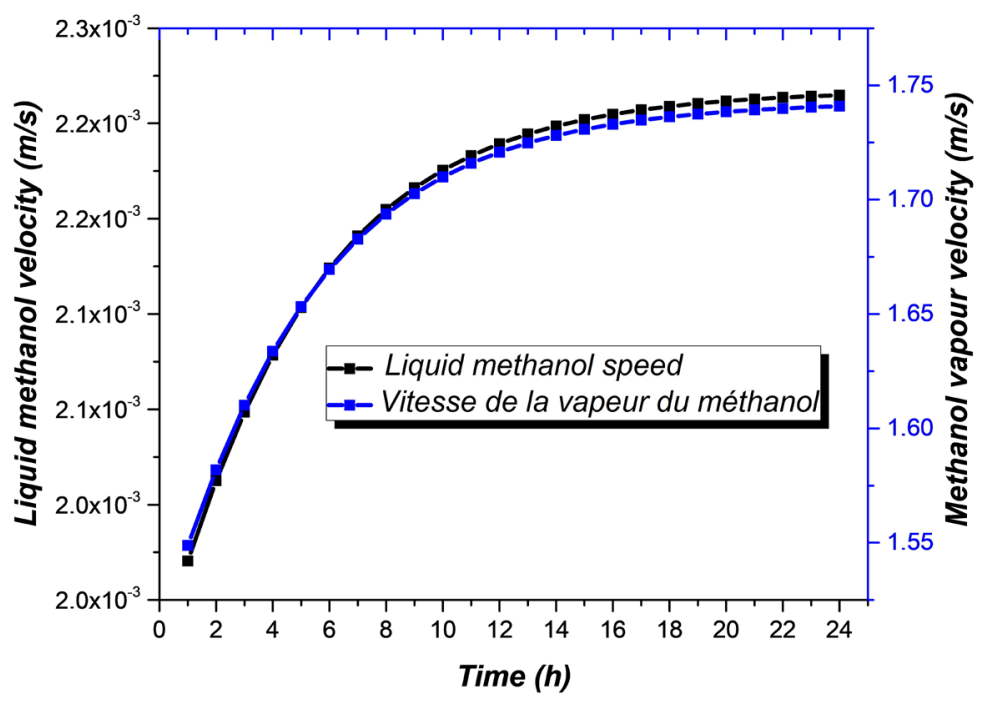

Figure 12. Fluid flow velocity in the riser and downcomer.

and vapour state. The maximum flow velocity value at the downcomer is about $2.2 \times 10^{-3} \mathrm{~m} / \mathrm{s}$ and that of the vapour at the riser is about $1.73 \mathrm{~m} / \mathrm{s}$.

\section{Conclusions}

Heat transfer modelling and simulation of a two-phase thermosyphon loop is performed. The simulation results of this study are presented and show that the temperature at the evaporator walls drops from $23^{\circ} \mathrm{C}$ to $13^{\circ} \mathrm{C}$, which justifies that the system is capable of cooling. The mass flow rates and masses at the evaporator and condenser increase with temperature. The variation in evaporating and condensing temperature affects the performance of the system. For a constant evaporating and condensing temperature of $2^{\circ} \mathrm{C}$ and $29^{\circ} \mathrm{C}$, the COP is 0.77 and 0.84 respectively. It has been found that the solar flux density and the evaporator surface area have a great influence on the air conditioning system. Therefore, to cool a room such as a house, a large evaporator surface is required.

From these results, we can see that the natural phase change two-phase thermosiphon loop has an excellent heat transfer capacity at low cost and without any electricity consumption. This system will therefore be an effective solution in the future for thermal comfort in the home, which is considered to be one of the largest energy consumers in the world. This study will be continued in order to couple with our habitat model to maintain the internal air temperature of the living space by natural convection.

\section{Conflicts of Interest}

The authors declare no conflicts of interest regarding the publication of this paper.

\section{References}

[1] Huang, Y. and Li, C. (2021) Accurate Heating, Ventilation and Air Conditioning 
System Load Prediction for Residential Buildings Using Improved Ant Colony Optimization and Wavelet Neural Network. Journal of Building Engineering, 35, Article ID: 101972. https://doi.org/10.1016/j.jobe.2020.101972

[2] Opoku, R., Mensah-Darkwa, K. and Samed Muntaka, A. (2018) Techno-Economic Analysis of a Hybrid Solar PV-Grid Powered Air-Conditioner for Daytime Office Use in Hot Humid Climates-A Case Study in Kumasi City, Ghana. Solar Energy, 165, 65-74. https://doi.org/10.1016/j.solener.2018.03.013

[3] Charbonneau, J.Y., Douville, S., Schreiber, L. and Lemaire, J. (2004) Confort thermique à l'intérieur d'un établissement. Commission de la santé et de la sécurité du travail du Québec, Direction de la prévention-inspection, Direction des communications.

[4] Cao, J., Hong, X., Zheng, Z., Asim, M., Wang, Q. and Leung, M.K. (2020) Performance Characteristics of Variable Conductance Loop Thermosyphon for Energy-Efficient Building Thermal Control. Applied Energy, 275, Article ID: 115337. https://doi.org/10.1016/j.apenergy.2020.115337

[5] Samba, A., Hasna, L.G., Le Masson, S. and Nörterhäuser, D. (2013) Two-Phase Thermosyphon Loop for Cooling Outdoor Telecommunication Equipments. Applied Thermal Engineering, 50, 1351-1360. https://doi.org/10.1016/j.applthermaleng.2012.05.023

[6] Han, L., Shi, W., Wang, B., Zhang, P. and Li, X. (2013) Development of an Integrated Air Conditioner with Thermosyphon and the Application in Mobile Phone Base Station. International Journal of Refrigeration, 36, 58-69. https://doi.org/10.1016/j.ijrefrig.2012.09.012

[7] Zhu, L., Yang, Y., Chen, S. and Sun, Y. (2019) Thermal Performances Study on a Façade-Built-In Two-Phase Thermosyphon Loop for Passive Thermo-Activated Building System. Energy Conversion and Management, 199, Article ID: 112059. https://doi.org/10.1016/j.enconman.2019.112059

[8] Tong, Z., Liu, X. and Jiang, Y. (2017) Experimental Study of the Self-Regulating Performance of an R744 Two-Phase Thermosyphon Loop. Applied Energy, 186, 1-12. https://doi.org/10.1016/j.apenergy.2016.10.121

[9] Ding, T., He, Z.G., Hao, T. and Li, Z. (2016) Application of Separated Heat Pipe System in Data Center Cooling. Applied Thermal Engineering, 109, 207-216. https://doi.org/10.1016/j.applthermaleng.2016.08.025

[10] Khodabandeh, R. (2004) Thermal Performance of a Closed Advanced Two-Phase Thermosyphon Loop for Cooling of Radio Base Stations at Different Operating Conditions. Applied Thermal Engineering, 24, 2643-2655.

https://doi.org/10.1016/j.applthermaleng.2004.05.006

[11] Chehade, A., Lemasson, S. and Louhahlia-Gualous, H. (2013) Etude des Performances Thermiques d'une Boucle Diphasique Fonctionnant avec un Nanofluide. 21 ème Congrès Français de mécanique, Bordeaux.

[12] Zhang, P., Wang, B., Shi, W., Han, L. and Li, X. (2015) Modeling and Performance Analysis of a Two-Phase Thermosyphon Loop with Partially/Fully Liquid-Filled Downcomer. International Journal of Refrigeration, 58, 172-185. https://doi.org/10.1016/j.ijrefrig.2015.06.014

[13] Camara, Y., Chesneau, X. and Kanté, C. (2018) Etude numérique du confort thermique dans un habitat bioclimatique en brique de terre stabilisée pour un climat type de la Guinée. Afrique Science, 14, 238-254.

[14] Oudrane, A., Aour, B., Zeghmati, B., Chesneau, X. and Hamouda, M. (2017) Analyse numerique de transfert thermique unidimensionnel d'une enceinte habitable 
desertique. Recueil de Mécanique, 2, 89-102.

[15] Khalifa, A.J.N. (2001) Natural Convective Heat Transfer Coefficient-A Review: I. Isolated Vertical and Horizontal Surfaces. Energy Conversion and Management, 42, 491-504. https://doi.org/10.1016/S0196-8904(00)00042-X

[16] Salem, M.A.E.M. (2010) Experimental Study for Transient Response of a Double-Tube Thermosyphon (DTTH). Thèse de Doctorat à Al-Azhar Universty, Cairo, Egypt.

[17] Naresh, Y. and Balaji, C. (2018) Thermal Performance of an Internally Finned Two Phase Closed Thermosyphon with Refrigerant R134a: A Combined Experimental and Numerical Study. International Journal of Thermal Sciences, 126, 281-293. https://doi.org/10.1016/j.ijthermalsci.2017.11.033 


\section{Highlights}

- A two-phase thermosyphon loop is developed to show its feasibility in passive air-conditioning of housing;

- The thermal performance of the loop air conditioning system has been determined;

- The temperature on the walls of the evaporator drops from $25^{\circ} \mathrm{C}$ to $13^{\circ} \mathrm{C}$ with methanol and can be used to cool the ambient temperature of a room to be air conditioned.

\section{Nomenclature}

$C O P_{t h}$ : Coefficient of thermal performance;

$C p$ : Heat capacity $(\mathrm{J} / \mathrm{kg} \cdot \mathrm{K})$;

$D F$ : Absorbed solar flux density $\left(\mathrm{W} / \mathrm{m}^{2}\right)$;

d: Diameter (m);

$e_{p}$ : Wall thickness (m);

$F$ : Geometric form factor;

$G_{n}$ : Incident solar flux density $\left(\mathrm{W} / \mathrm{m}^{2}\right)$;

$h_{x i j}$. Heat transfer coefficient according to the transfer mode $x\left(\mathrm{~W} / \mathrm{m}^{2} \cdot \mathrm{K}\right)$;

$h_{c}$ : Convection heat transfer coefficient $\left(\mathrm{W} / \mathrm{m}^{2} \cdot \mathrm{K}\right)$;

$h_{r}$ : Radiation heat transfer coefficient $\left(\mathrm{W} / \mathrm{m}^{2} \cdot \mathrm{K}\right)$;

$h_{\text {cond. }}$ Conduction heat transfer coefficient $\left(\mathrm{W} / \mathrm{m}^{2} \cdot \mathrm{K}\right)$;

$h_{f g}:$ Latent heat of vaporization $(\mathrm{J} / \mathrm{kg})$;

$L$ : Length (m);

m: Mass (kg);

$\dot{m}$ : Mass flow rate $(\mathrm{kg} / \mathrm{s})$;

Nu: Nusselt number;

Pu: Unit power $\left(\mathrm{W} / \mathrm{m}^{2} \cdot \mathrm{K}\right)$;

$P$. Vapour saturation pressure $(\mathrm{Pa})$;

Pr. Prandtl number;

$Q_{\text {chaleur: }}$ Amount of energy (W);

$Q_{f}$ Amount of cold (W);

Ra: Rayleigh number;

$S$ : Area $\left(\mathrm{m}^{2}\right)$;

T: Temperature (K);

$t$. Time (s);

$U$ : Flow velocity $(\mathrm{m} / \mathrm{s})$;

$V$ : Wind velocity $(\mathrm{m} / \mathrm{s})$;

w. Mass fraction;

$\Delta x$. Step length (m).

\section{Greek Symbols}

$\alpha$ : Coefficient of absorptivity;

$\Phi_{i}$ : Heat source or sink $\left(\mathrm{W} / \mathrm{m}^{2}\right)$; 
$\beta_{m}$ : Coefficient of mass expansion $\left(\mathrm{K}^{-1}\right)$;

$\sigma$ : Stefan-Boltzmann constant $\left(5.67 \times 10^{-8} \mathrm{Wm}^{2} \cdot \mathrm{K}^{-4}\right)$;

$\varepsilon:$ Emissivity of the wall;

$\rho:$ Density $\left(\mathrm{kg} / \mathrm{m}^{3}\right)$;

$\lambda$ : Thermal conductivity $(\mathrm{W} / \mathrm{m} \cdot \mathrm{K})$;

$\sigma_{f}:$ Superficial tension $(\mathrm{N} / \mathrm{m})$;

$\mu$ : Dynamic viscosity $(\mathrm{kg} / \mathrm{m} \cdot \mathrm{s})$.

\section{Subscripts}

vs. Saturated vapour;

v. Vapour;

e. Evaporator;

c. Condenser;

f. Fluid;

1: Liquid;

$c d$ : Condensation;

ev. Evaporation;

Id: Liquid in downcomer;

sat: Saturation;

id: Inside of the downcomer;

ir. Inside of the riser. 